\title{
Itaipu Binacional Hydro Power Plant Thrust Bearing Design Optimization for Higher Efficiency
}

\author{
Piotr Pajaczkowski ${ }^{1}$, Michel Spiridon ${ }^{1}$, Andreas Schubert ${ }^{1}$, Geraldo Carvalho Brito Junior ${ }^{2}$ and João Maria \\ Marra $^{2}$ \\ 1. Alstom Renewable, Birr 5734, Switzerland \\ 2. Itaipu Binacional, Foz do Iguacu 4108304, Brazil
}

Received: December 17, 2014 / Accepted: January 05, 2015 / Published: February 25, 2015.

\begin{abstract}
Hydro generators installed in Itaipu Binacional power plant with 824/737 MVA rated output power (50/60 Hz) belong to the largest ones in the world. Among many unique features, the generators are equipped with the largest hydrodynamic thrust bearings ever built (external diameter 5,200 mm, axial load equals approximately 3,600 t). This paper is an attempt to propose a new thrust bearing design with the use of the state-of-the-art technologies and simulation techniques that demonstrate a reduction of friction power losses generated by the thrust bearing. This paper is divided into two parts. Within the first one, the original thrust bearing design which was implemented in the generators is described. Related calculation results based on a TEHD (thermo-elasto-hydrodynamic) calculation software used by Alstom will be presented. A comparison between measurement results gathered in the 1980s is given. In the second part, a potential solution of a more beneficial bearing design is described. The proposed thrust bearing design modification is an implementation of Alstom's Polypad ${ }^{\mathrm{TM}}$ coating. This modern polymer (PEEK) coating material has already been used by Alstom in projects around the world for many years. This coating allows pushing the operating parameters limits toward higher temperatures and lower oil film thicknesses far beyond the limits known for the conventional bearing materials.
\end{abstract}

Key words: Hydrodynamic thrust bearings, simulations, measurements.

\section{Introduction}

Hydro generators installed in Itaipu Binacional power plant with $824 / 737$ MVA rated output power $(50 / 60 \mathrm{~Hz})$ belong to the largest ones in the world. Among many unique features, the generators are equipped with the largest hydrodynamic thrust bearings ever built (external diameter 5,200 mm, axial load can reach up to approximately 3,600 t). It has been more than 30 years since these thrust bearings were designed. During this time, some significant developments in bearing technologies as well as in simulation techniques have been observed. This paper is an attempt to propose a new thrust bearing design with the use of the state-of-the-art technologies and simulation techniques

Corresponding author: Piotr Pajaczkowski, Ph.D., research fields: large hydrodynamic bearings simulations and measurements, rotor dynamics of vertically aligned machines. E-mail: Piotr.Pajaczkowski@power.alstom.com. that demonstrate a reduction of friction power losses generated by the thrust bearing and improve efficiency of the whole generator. The general idea is to bring the bearing design closer to the limits of the operational safety but without exceeding these limits. Operational safety limits for hydrodynamic bearings are described in Ref. [1] in details. This goal can be achieved only if the calculation methods allow maintaining satisfactory accuracy during the design phase. This study will show first of all validation of the calculation model with the use of measurement data. Afterwards, a comparison of an existing design (Fig. 1) with the new bearing proposal is described. Finally, the results of a heavily loaded thrust bearing under transient load are presented. The paper is organized as follows: Section 2 describes used calculation model; Section 3 presents the model validation and calculation results; finally, Section 4 gives the final conclusions. 

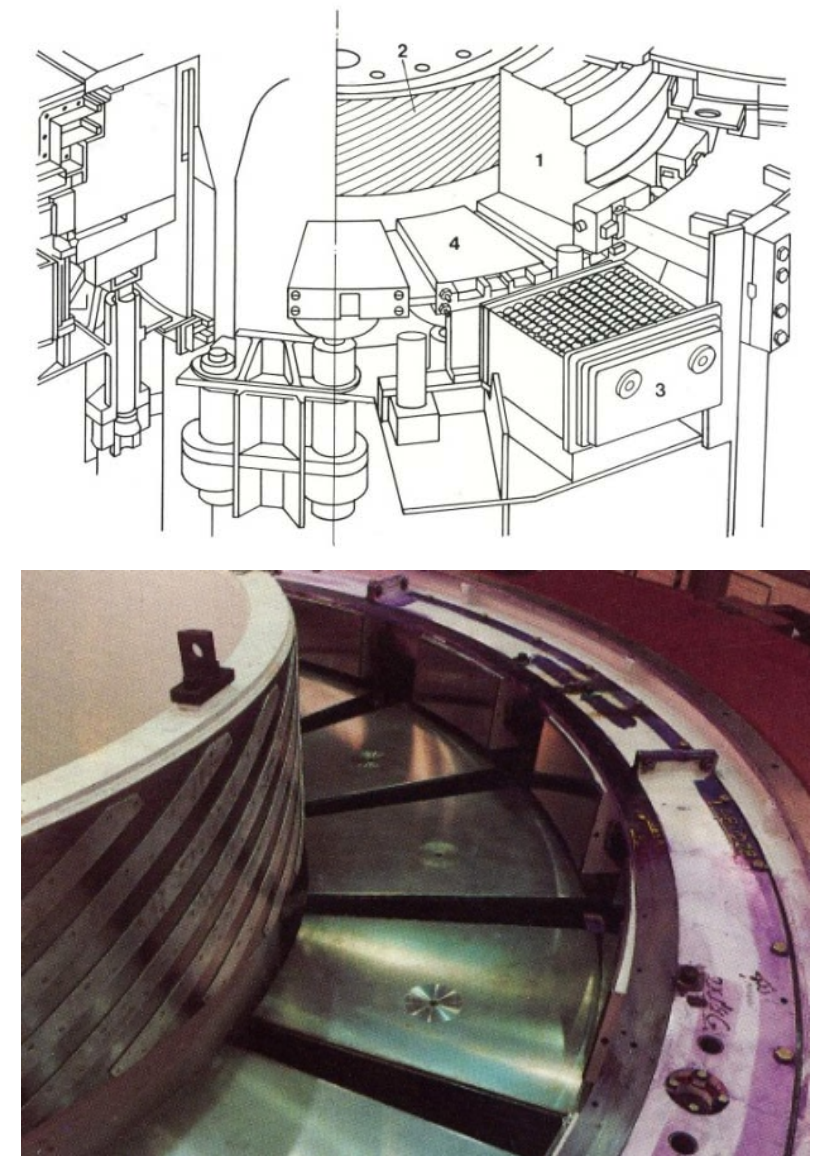

Fig. 1 Thrust bearing of an Itaipu hydro generator [2]: (1) thrust runner; (2) generator lower shaft; (3) thrust bearing oil to water heat exchanger; and (4) thrust pad.

\section{Calculation Model}

Related calculation results based on TEHD (thermo-elasto-hydrodynamic) calculation software, used by Alstom, are presented in this chapter. This program allows taking into account most of significant effects that occur within the bearing oil film and within the spaces between the thrust pads, like:

- three-dimensional temperature and viscosity treatment;

- heat transfer between oil film and bearing components (pad coating, pad body and runner);

- laminar to turbulent oil flow transition;

- mixing effects between thrust pads;

- cavitation in divergent oil film zones;

- coupling with an external finite elements program for prediction of the thermo-elastic deformations of the bearing components.
The iterative calculation process within this program is based on three iteration loops. The most internal loop (hydraulic coupling) solves hydrodynamic Reynolds equation for velocity and pressure fields. Within the second iteration loop, the energy equations are solved in order to estimate heat dissipation and transfer, temperatures and finally viscosity fields (energetic coupling). Within the most outer loop, the balance of the bearing elements and the tilt position of the pad are estimated (mechanical coupling). More detailed description of the calculation software can be found in Ref. [3].

Due to large size of the bearing parts, their thermoelastic deformations have to be considered with high accuracy [5]. Two FE (finite elements) models are coupled with the bearing simulation tool for estimation of the thermo-elastic pad and runner deformations. Resulting deformations are imposed in the following iteration of the bearing calculation program. The iterative process is carried on until the main operating parameters of the bearing stabilize - change between two subsequent iterations is lower than $1 \%$. An example of calculation result from FE calculation program is given in Fig. 2.

In order to simulate bearing behavior with the highest possible accuracy, the thermal and mechanical properties of the polymer coating material are based on the measured values which are listed in Table 1.

Structure of the Polypad ${ }^{\mathrm{TM}}$ coating is given in Fig. 3. A layer of PEEK (poly ether ether ketone) is mechanically bonded with steel backing of the pad by the means of sintered bronze technology. Thickness of the whole composite layer equals approximately $3 \mathrm{~mm}$.

\section{Model Validation and Calculation Results}

\subsection{Validation of the Model with Measurement Data}

A comparison between measurement results gathered in the 1980s for the purpose of the calculation model validation is given. Measurements performed at site allowed to collect a large number of important information about the bearing condition. All the most 


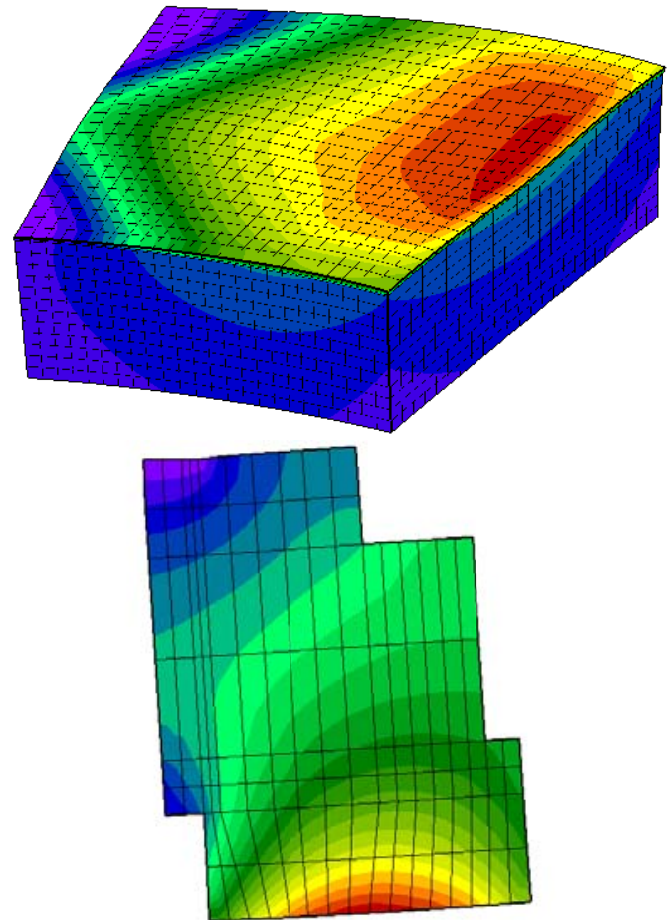

Fig. 2 FE calculation results for pad and runner, temperature fields and thermo-elastic deformations.

Table 1 Thermal and mechanical properties of Polypad ${ }^{\mathrm{TM}}$ coating material.

\begin{tabular}{lll}
\hline Parameter & Value & Unit \\
\hline Mechanical strength @ $100{ }^{\circ} \mathrm{C}$ & 150 & $\mathrm{MPa}$ \\
Bonding shear strength @ $120{ }^{\circ} \mathrm{C}$ & 28 & $\mathrm{MPa}$ \\
Young module & 3.5 & $\mathrm{GPa}$ \\
Thermal conductivity & 0.4 & $\mathrm{~W} / \mathrm{m} \mathrm{K}$ \\
Melting point temperature & 343 & ${ }^{\circ} \mathrm{C}$ \\
Dry friction coefficient & 0.1 & - \\
\hline
\end{tabular}

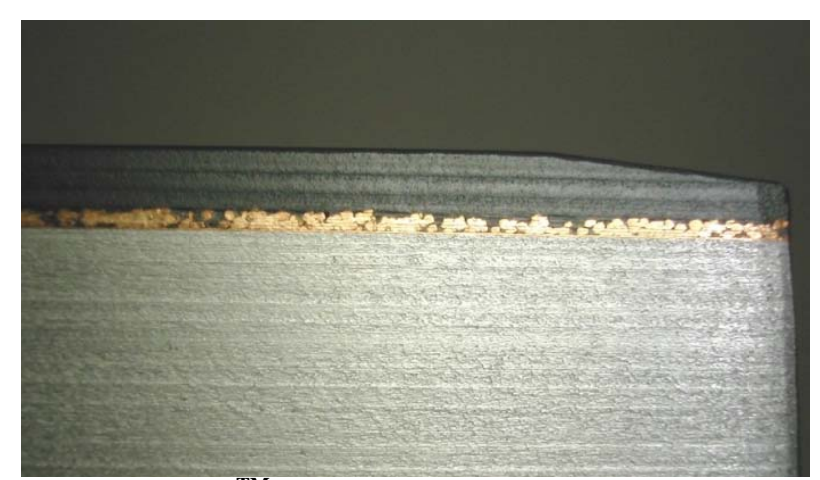

Fig. 3 Polypad $^{\mathrm{TM}}$ coating with sintered bronze bonding technology.

important bearing parameters were measured during these tests: oil film thickness and hydrodynamic pressure profiles with the use of sensors installed inside the thrust runner and several temperatures collected from the thrust runner ( 7 sensors) and two thrust pads (25 sensors) parts as well as within the space between the thrust pads ( 10 sensors).

During an extensive measurement campaign realized at site in 1980s, a large amount of operational data was collected. For simplicity, only the results from nominal operation point are shown. The bearing related operational parameters are summarized in Table 2, and geometrical properties of the bearing are listed in Table 3. Rated load was increased by $6 \%$ in order to fit more accurately the load value that was acting on the test pad during the measurements.

Comparison between measured and calculated oil film thickness profiles at average radius $(R=2,112.5$ $\mathrm{mm}$ ) is given in Fig. 4. Calculated profile indicated slightly lower oil film thickness profile. Calculated minimum oil film thickness equals $52.2 \mu \mathrm{m}$ whereas the measured value equals $67 \mu \mathrm{m}$. The calculated oil film inlet height equals $249 \mu \mathrm{m}$ compared to the measured $358 \mu \mathrm{m}$. Outlet to inlet height ratios of 4.77 (calculated) and 5.34 (measured) indicate that the

Table 2 Operational parameters during measurement at rated load.

\begin{tabular}{lll}
\hline Parameter & Value & Unit \\
\hline Rotational speed & 92 & $\mathrm{rpm}$ \\
Thrust load $(27.7 \times 1.06)$ & 29.4 & $\mathrm{MN}$ \\
Oil grade & 54 & $\mathrm{ISO} \mathrm{VG}$ \\
Cold oil temperature (cooler outlet) & 40 & ${ }^{\circ} \mathrm{C}$ \\
Warm oil temperature (cooler inlet) & 50 & ${ }^{\circ} \mathrm{C}$ \\
\hline
\end{tabular}

Table 3 Comparison of the main properties of the thrust bearings.

\begin{tabular}{llll}
\hline Parameter & Existing & Proposed & Unit \\
\hline Outer diameter & 5,200 & 4,250 & $\mathrm{~mm}$ \\
Inner diameter & 3,250 & 3,250 & $\mathrm{~mm}$ \\
Pad thickness & 230 & 150 & $\mathrm{~mm}$ \\
Number of pads & 16 & 24 & - \\
Pad angle & 18.5 & 13 & $\mathrm{deg}$ \\
Support pos. in tangential dir. & 0.60 & 0.60 & - \\
Support pos. in radial dir. & 0.50 & 0.50 & - \\
$\begin{array}{l}\text { Coating material } \\
\text { Taper design }\end{array}$ & Babbitt & Polypad $^{\mathrm{TM}}$ & - \\
$\begin{array}{l}\text { Rated specific pressure } \\
(29.4 \mathrm{MN})\end{array}$ & Without & With & - \\
$\begin{array}{l}\text { Transient specific pressure } \\
(36.0 \mathrm{MN})\end{array}$ & 2.76 & 5.76 & $\mathrm{MPa}$ \\
\hline
\end{tabular}




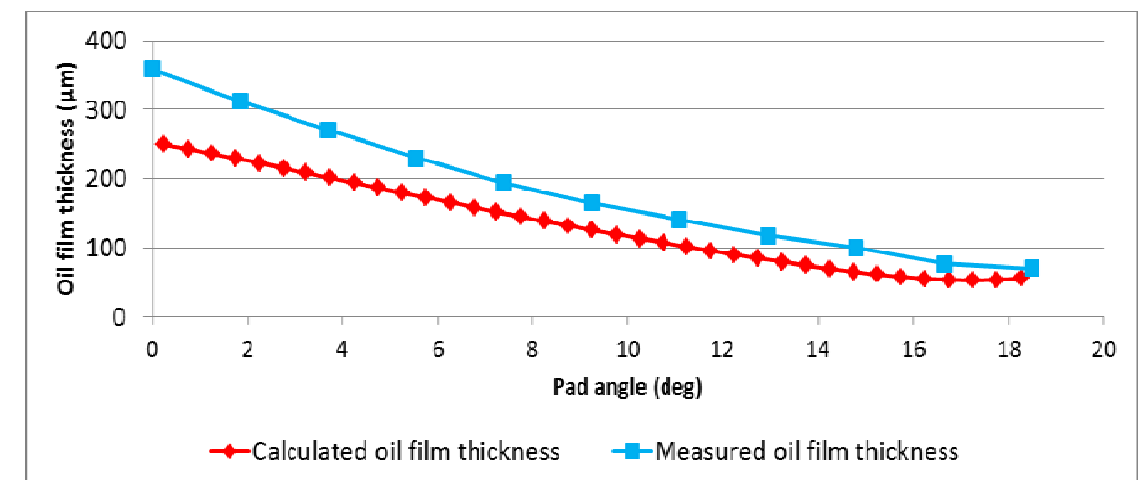

Fig. 4 Comparison of the measured and calculated oil film thickness profiles on the average radius $R=2,112.5 \mathrm{~mm}$.

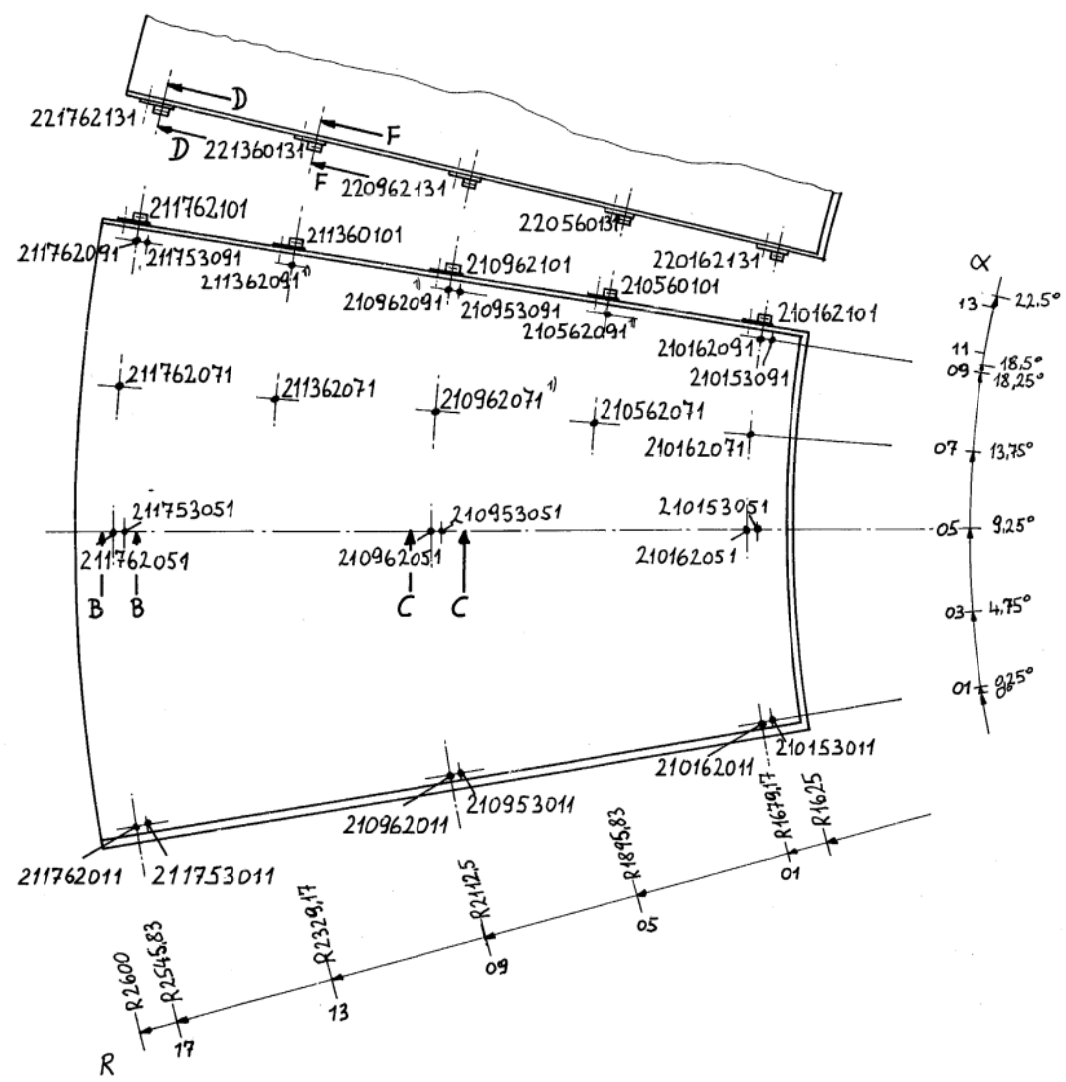

Fig. 5 Distribution of the temperature sensors on the pad surface.

hydrodynamic behaviour of the pad is estimated more accurately than could be observed from the absolute values of the oil film gap.

The original technical drawing from 1981 with temperature sensors positions is presented in Fig. 5.

Measured and calculated temperature profiles are presented in Fig. 6. Generally quite good agreement has been achieved. The calculated temperature profiles on the inner $(R=1,679.2 \mathrm{~mm})$ and outer $(R=$ $2,545.8 \mathrm{~mm})$ pad edges fit almost exactly to the measured ones. The calculated temperatures on the average radius $(R=2,112.5 \mathrm{~mm})$ are lower than the measured ones. Temperatures values are in a very good agreement on the leading and trailing edges.

On the measured hydrodynamic pressure profile, presented in Fig. 7, one can clearly see influence of the hydrostatic jacking chamber-region with constant pressure value. In the simulation model, this sliding surface feature was not included, so the pressure profile has more ordinary shape. 


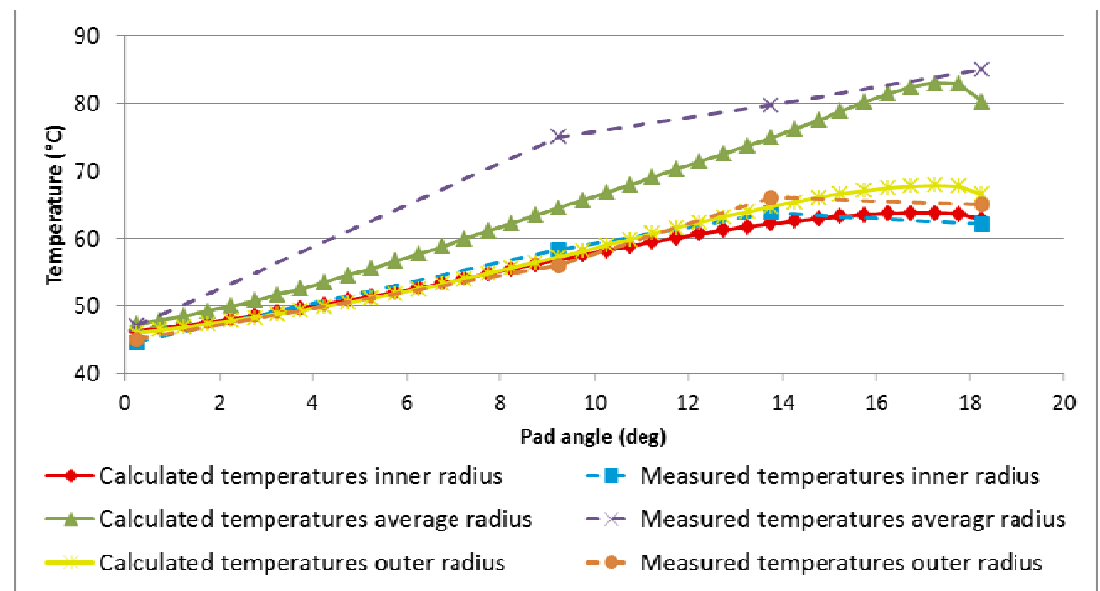

Fig. 6 Comparison of the measured and calculated temperature profiles on the inner, average and outer radius, $6 \mathrm{~mm}$ under the sliding surface.

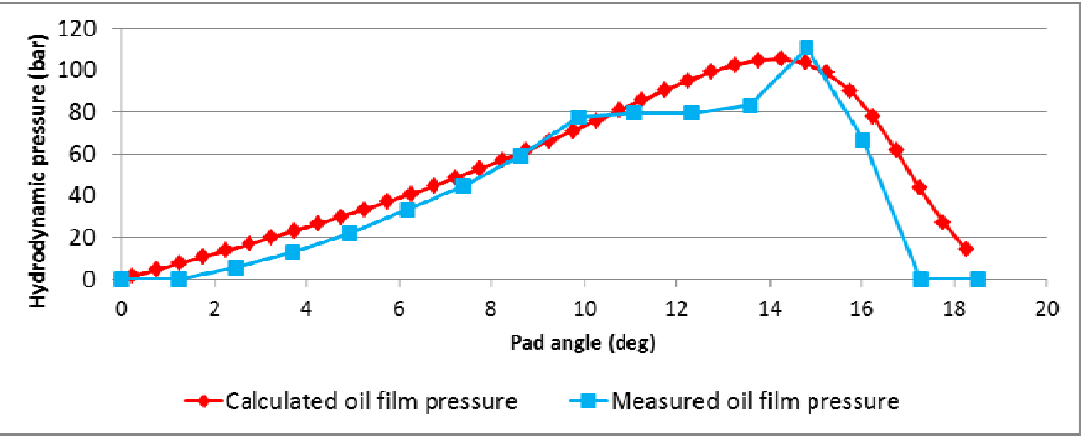

Fig. 7 Comparison of the measured and calculated oil film pressure profiles (average radius $R=2,112.5 \mathrm{~mm}$ ).

The model validation with measured data indicated that the simulation results are close to the measured values with a tendency of the estimation being rather on the pessimistic side. Calculated oil film thickness is lower than the measured one but the tilt ratio remained similar. Calculated and measured temperatures $6 \mathrm{~mm}$ below the pad sliding surface are close to each other except to the points in the middle of the pad, where measured values are higher. This discrepancy is difficult to explain and is present also in calculations of Itaipu thrust bearing done by other researchers [4]. Most probably, it is caused by the manufacturing inaccuracy in the sliding surface profile.

\subsection{New Thrust Bearing Design Proposal}

Since the thrust bearings for Itaipu generators were designed with the use of materials and technology available in 1970s, their configuration has still significant optimization potential. In this chapter, a proposal of a more beneficial bearing design is described. The goal of the optimization is to limit the power losses (efficiency improvement) resulting from the bearing dimensions reduction and an increase of the bearing specific load. It is not the aim of this article to perform a comprehensive redesign of the current Itaipu bracket and respective detailed modifications needed to accommodate the new bearing dimensions, otherwise to show the potential of latest bearing technology available in large machines. The proposed thrust bearing design modification is an implementation of Alstom's Polypad ${ }^{\mathrm{TM}}$ coating. This modern PEEK polymer coating material has already been used by Alstom in projects around the world for many years. This coating allows pushing the operating parameters limits toward higher temperatures and lower oil film thicknesses far beyond the limits known for the conventional bearing materials. Due to its 
thermal and mechanical strengths as well as high wear resistance, the bearings can be downsized and loaded with significantly higher loads. This brings significant efficiency improvements. Due to low thermal conductivity of the Polypad ${ }^{\mathrm{TM}}$ coating, the bearing pads have reduced thermal deformations compared to conventional materials, which additionally increases the load carrying capacity of the thrust bearing.

Due to need of compatibility with the existing shafts and brackets, the inner bearing diameter remained unchanged. Since the width of the pads had to be significantly reduced, in order to maintain value of the length to width ratio less than 1, it was necessary to increase number of the pads from 16 to 24. The existing bearing bracket has eight supporting arms, so with 24 thrust pads, it is still possible to maintain integer number of pads per arm. The covered surface factor (pads area/total ring area) increased from $82.2 \%$ for the existing design to $86.6 \%$ for the new one. The main dimensions of both thrust bearings are compared in Fig. 8 and Table 3.

High loaded bearings tend to operate with lower oil film inlet/outlet height ratio which leads to increased oil film inlet temperatures. In order to improve this parameter, new bearing makes use of the oil film inlet/outlet taper design feature. The authors carefully investigated this modification of the sliding surface. It has been described in detail in Refs. [6-8] and already successfully implemented in several hydro generator thrust bearings. The main goal of this modification is to increase artificially the pad crowning in circumferential direction and to let more fresh oil to enter the oil film. In general, it enables bidirectional and/or polymer coated and/or heavily loaded bearings to operate at lower temperatures.

Comparison of the main calculation results of the both thrust bearing designs is given in Table 4. During design of the modified bearing, an optimization process has been carried out in order to identify the most favorable profile (taper depth and length) of the sliding surface.

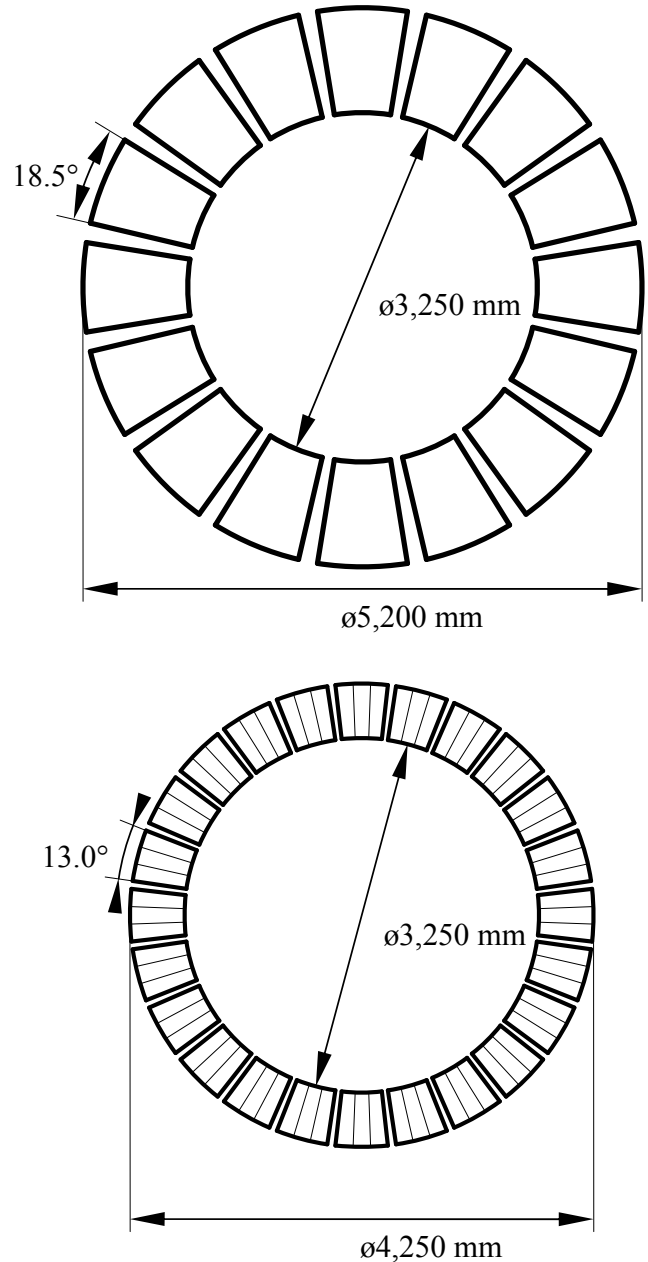

Fig. 8 Comparison of the bearing designs, upper: old bearing, lower: new bearing with polymer coating and tapered sliding surface.

Table 4 Comparison of the main operating parameters at rated load.

\begin{tabular}{|c|c|c|c|}
\hline Parameter & Existing & Proposed & Unit \\
\hline Minimum oil film th. & 52.2 & 26.9 & $\mu \mathrm{m}$ \\
\hline Maximum oil film temp. & 84.9 & 94.5 & ${ }^{\circ} \mathrm{C}$ \\
\hline $\begin{array}{l}\text { Pad temperature at } 0.5 \mathrm{R} / 0.75 \\
\mathrm{~L} / 6 \mathrm{~mm}\end{array}$ & 75 & 59 & ${ }^{\circ} \mathrm{C}$ \\
\hline Maximum runner def. & 58.1 & 42.0 & $\mu \mathrm{m}$ \\
\hline Maximum runner temp. & 69.5 & 81.1 & ${ }^{\circ} \mathrm{C}$ \\
\hline Maximum oil film pressure & 10.7 & 17.3 & $\mathrm{MPa}$ \\
\hline Max / specific press ratio & 3.9 & 3.0 & - \\
\hline Power losses thrust bearing & 572.8 & 325.3 & $\mathrm{~kW}$ \\
\hline Power losses guide bearing & 319.7 & 176.8 & $\mathrm{~kW}$ \\
\hline Total power losses & 892.5 & 502.1 & $\mathrm{~kW}$ \\
\hline $\begin{array}{l}\text { Required cooling oil flow for } \\
\Delta T=10^{\circ} \mathrm{C}\end{array}$ & 3,157 & 1,776 & $\mathrm{~L} \cdot \mathrm{min}^{-1}$ \\
\hline $\begin{array}{l}\text { Required minimum oil tank } \\
\text { capacity }\end{array}$ & 12,628 & 7,104 & $\mathrm{dm}^{3}$ \\
\hline
\end{tabular}


Due to smaller size of the polymer coated bearing, it was possible to reduce its power losses by $43.2 \%$ from $572 \mathrm{~kW}$ to $325 \mathrm{~kW}$. Estimated power loss savings for the guide bearing are also high-reduction from $319.7 \mathrm{~kW}$ to $176.8 \mathrm{~kW}$. Consequently, total power loss of the combined thrust guide bearing decreased by $43.7 \%$ from $892.5 \mathrm{~kW}$ to $502.1 \mathrm{~kW}$. This significant total power loss reduction could potentially lead to downsizing of the cooling system and smaller oil amount required for the bearing. These savings are proportional to the power loss reduction rate.

Resulting oil film thickness profiles are shown in Fig. 9. The diagrams are always oriented in the same way with the oil film inlet on the left hand side and outlet on the right. Outer bearing diameter is located on the bottom edge. One can notice improvement in oil film inlet and outlet ratio due to

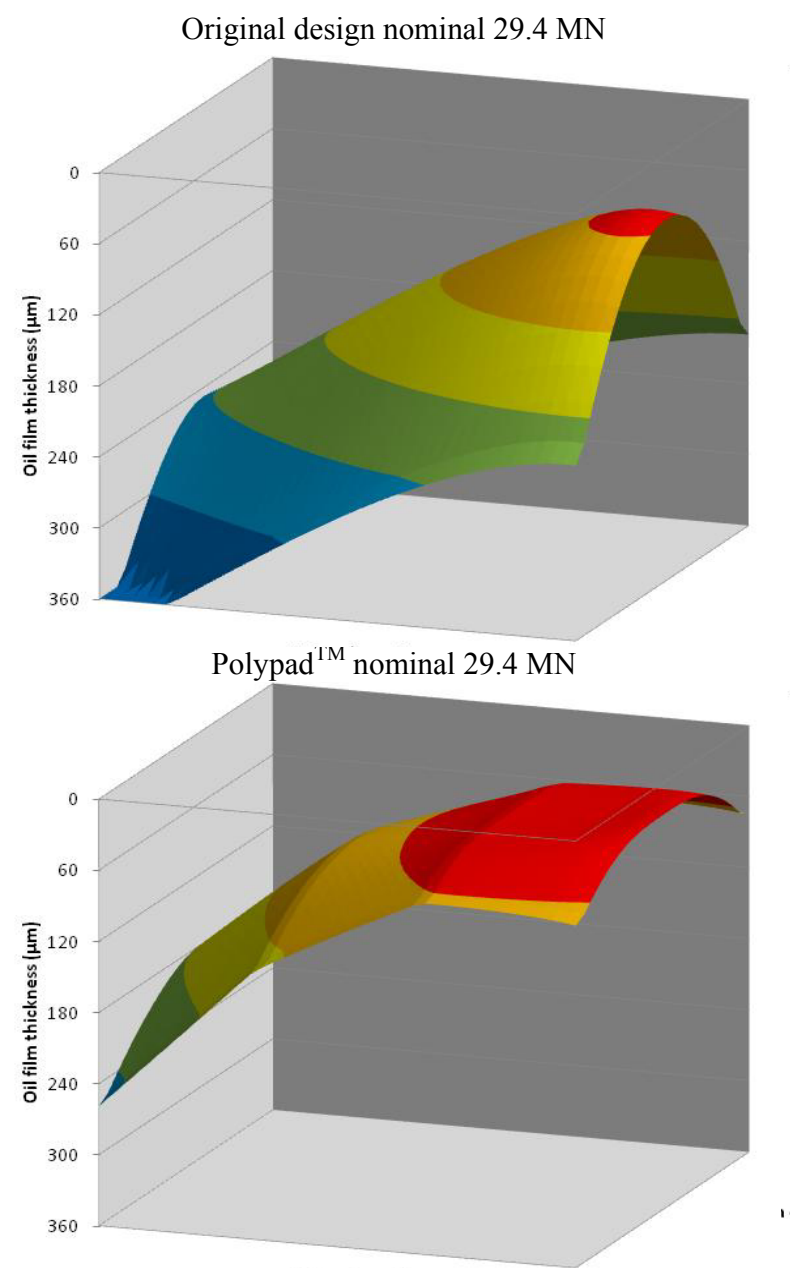

Fig. 9 Comparison of the oil film thickness profiles. tapered bearing design. Significantly lower deformations in radial direction result in more evenly distributed oil film thickness along the pad width.

Minimum calculated oil film thickness has decreased from $56.2 \mu \mathrm{m}$ for babbitted bearing to 27.0 $\mu \mathrm{m}$ for polymer coated one.

Deformations of the bearing pads are given in Fig. 10. One can easily notice a completely different character of the pad deformations for both bearings. While the conventional pad indicates strong thermal crowning in radial $(80 \mu \mathrm{m})$ and tangential $(30 \mu \mathrm{m})$ direction, the polymer coated pad creates a sort of concave pocket in the region of maximum pressure adjusting its shape to the convex runner.

Both surfaces do not deform anymore against each other but create more parallel oil film in the outlet zone. This kind of pad deformation has two reasons.

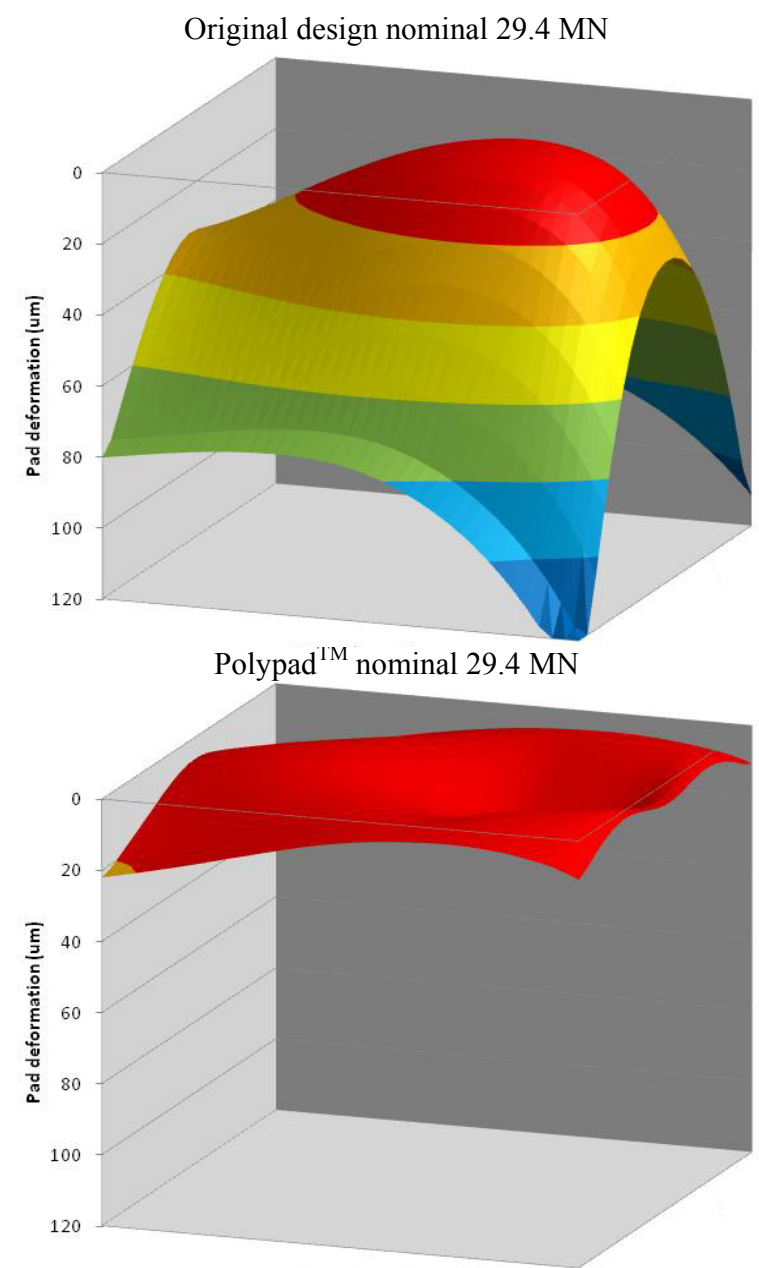

Fig. 10 Comparison of the thrust pad deformations. 
First of all elastic deformations of the polymer lining are significantly higher than those for babbitted pads. The Young modulus for Polypad ${ }^{\mathrm{TM}}$ is more than one order of magnitude lower than for Babbitt. At the same time, the pad thermal deformations are significantly reduced in case of polymer coated thrust bearing due to insulating properties of the lining material.

Even though the thrust bearing operates at slightly higher temperature, thanks to reduced width of the bearing, the thermal crowning of the thrust runner is lower in case of the polymer coated bearing. Similar like in case of the pad deformations, this effect contributes to load carrying capacity improvement. The resulting deformations of the sliding surfaces are shown in Fig. 11.

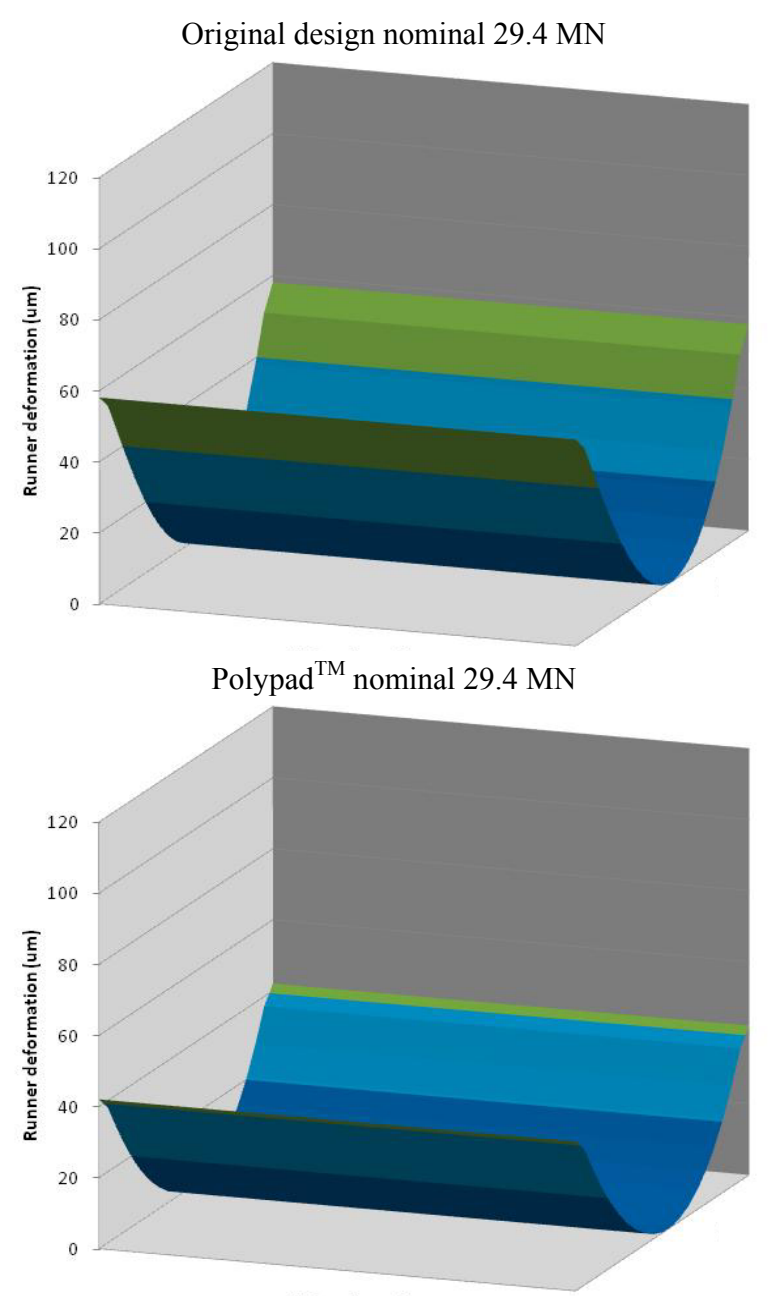

Fig. 11 Comparison of the thrust runner deformations.
Hydrodynamic pressure fields are compared in Fig. 12.

The maximum value is significantly higher in case of the polymer coated pad due to higher specific load, but the ratio between maximum and average value is lower (3.9 and 3.0, respectively). This indicates more uniform pressure distribution in the oil film. One can also observe this effect in Fig. 12, where the pressure profile of a polymer coated pad looks more "filled". This behavior has two reasons. First of all, pad and runner deformations in radial direction are significantly lower. Additionally, a "pocket" shape of pad surface decreases side leakages from the oil film.

Due to optimized tapered design, there is no divergent zone in the outlet region, which could potentially cause significant reduction of the pad surface.

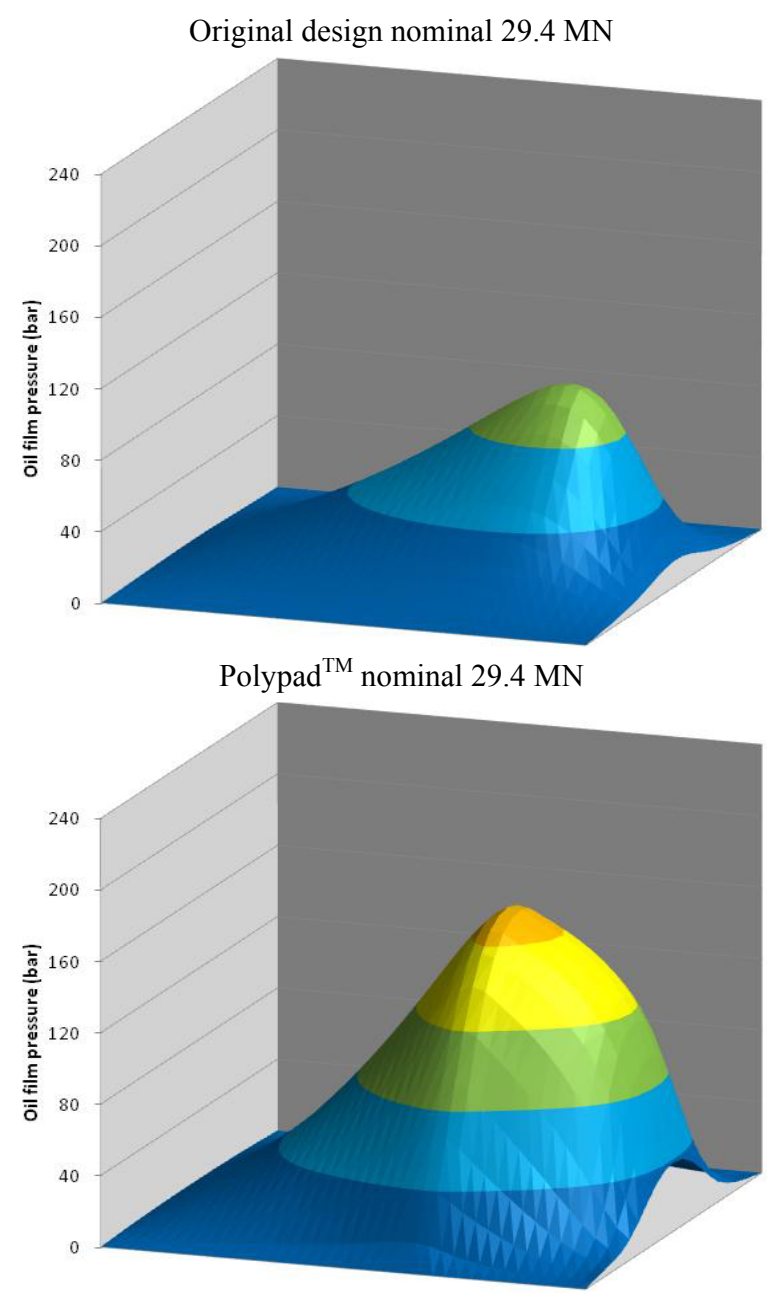

Fig. 12 Comparison of the hydrodynamic pressure fields. 
Temperature fields on the cross section through the oil film, the pad and the runner are given in Fig. 13. Even though the modified bearing reaches $10{ }^{\circ} \mathrm{C}$ higher temperature than the original design, the maximum value of $94.5{ }^{\circ} \mathrm{C}$ is well below limits defined even for conventional bearings, which are usually set above $100{ }^{\circ} \mathrm{C}$.

In Fig. 13, one can observe several interesting features of the calculation model. First of all, three-dimensional temperature fields within the oil film indicate strong temperature gradients through the oil film thickness, especially within the oil film outlet zone. The temperature contours are almost perpendicular to the pad sliding surface indicating small heat transfer rate through the pad. The steel backing of the polymer coated pad has significantly
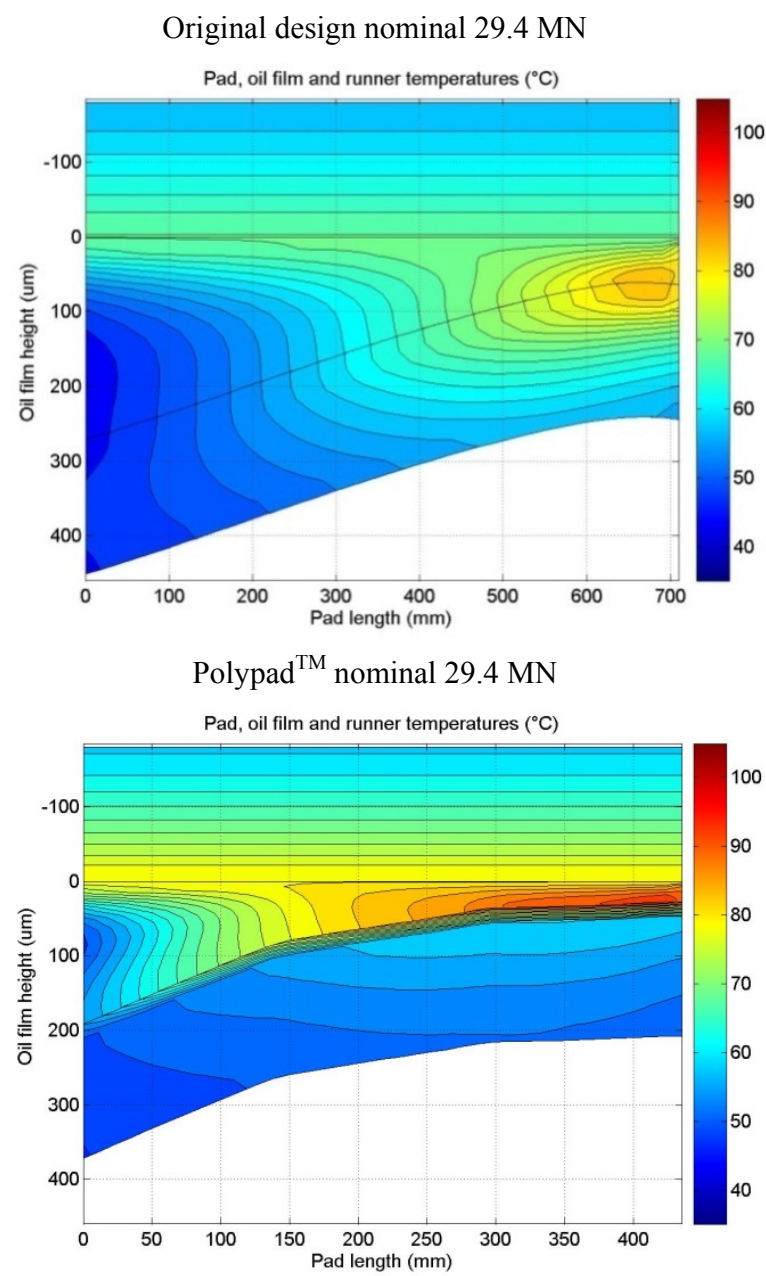

Fig. 13 Temperature fields on the cross section through the bearings for average radius $(R=2,112.5 \mathrm{~mm})$. lower temperature than the babbitted one.

Due to insulating properties of the polymer coating, the pad thermal deformations are significantly reduced. Additionally, it is clearly visible that the thermal boundary layer between the pads, called warm oil mixing, is also resolved and the oil film inlet temperature is resulting from this calculation. This feature can be even better seen on the oil film inlet (Fig. 14) and outlet (Fig. 15) temperature fields and oil film thickness profiles. Oil film inlet and outlet windows of a polymer coated bearing demonstrate significantly more parallel gap profile compared to the conventional bearing. This reduction of divergence in radial direction reduces side leakages and contributes to higher load carrying capacity.
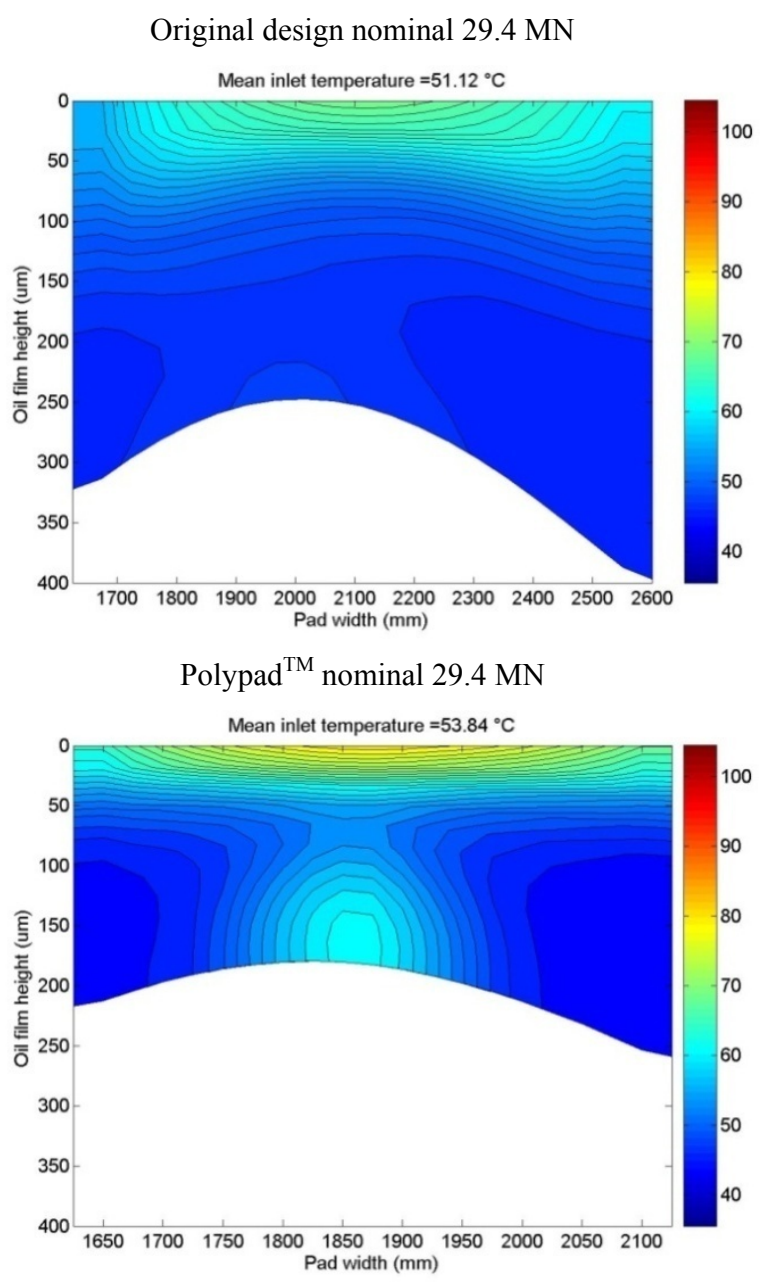

Fig. 14 Oil film inlet temperature fields. 


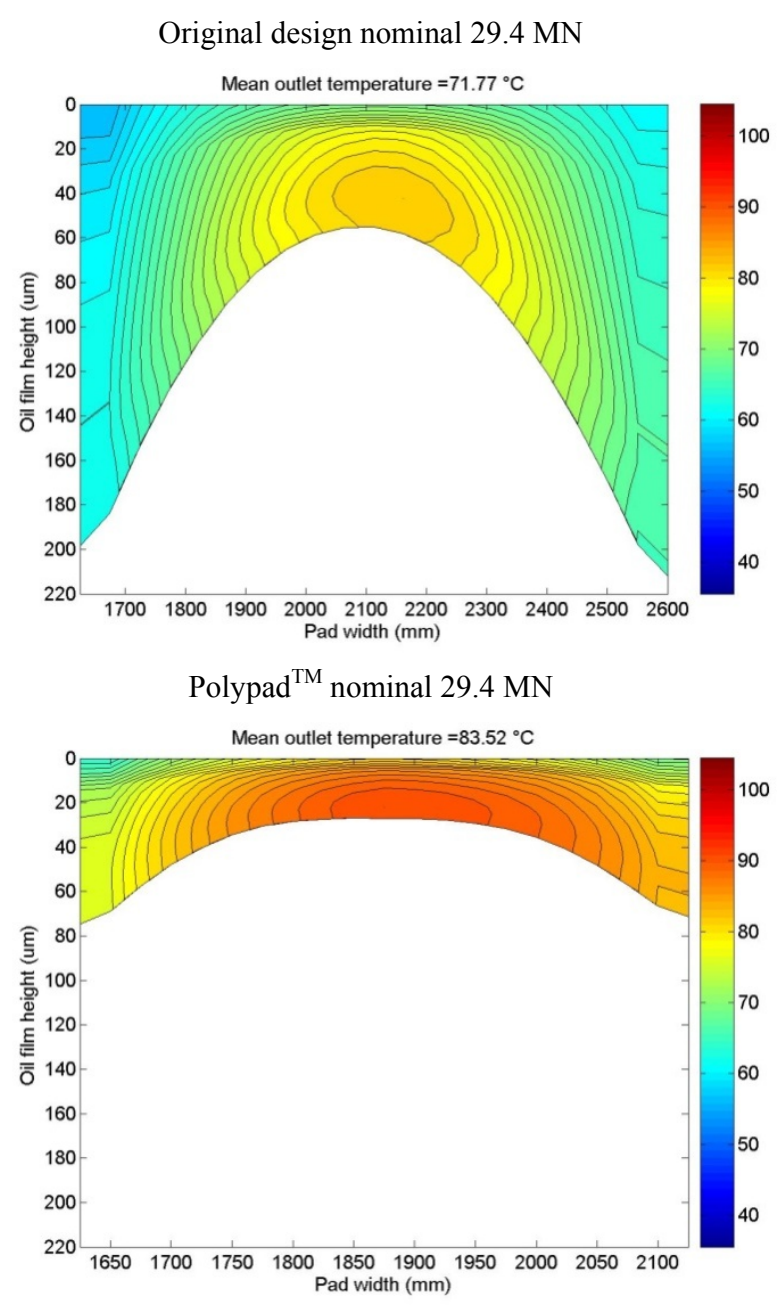

Fig. 15 Oil film outlet temperature fields.

\subsection{Calculation of the New Thrust Bearing under} Transient Load of $36 \mathrm{MN}$

The thrust bearing of a hydro generator has to be designed not only for the rated conditions but also for all fault cases that can occur during its lifetime. Commonly, during transient periods of operation (e.g., load rejection or runaway), thrust load is significantly higher than in rated condition. In this chapter, transient thrust load was assumed to equal $36 \mathrm{MN}$. This value is within the range of the maximum values expected in the Itaipu hydro generator. In this chapter, two calculations of the proposed new bearing design are compared-rated and transient condition. All parameters except the load remained unchanged. Main resulting operational parameters are listed in Table 5.
Table 5 Comparison of the main operating parameters at rated and transient load.

\begin{tabular}{llll}
\hline Parameter & Rated & Transient & Unit \\
\hline Minimum oil film th. & 26.9 & 21.5 & $\mu \mathrm{m}$ \\
Maximum oil film temp. & 94.5 & 99.0 & ${ }^{\circ} \mathrm{C}$ \\
Pad temperature at & 0.5 & 61 & ${ }^{\circ} \mathrm{C}$ \\
R/0.75 L/6 mm & 59 & 61 & \\
Maximum runner def. & 42.0 & 49.4 & $\mu \mathrm{m}$ \\
Maximum runner temp. & 81.1 & 87.1 & ${ }^{\circ} \mathrm{C}$ \\
Maximum oil film pressure & 17.3 & 22.9 & $\mathrm{MPa}$ \\
Max/specific press ratio & 3.0 & 3.2 & - \\
Power losses thrust bearing & 325.3 & 339.4 & $\mathrm{~kW}$ \\
\hline
\end{tabular}

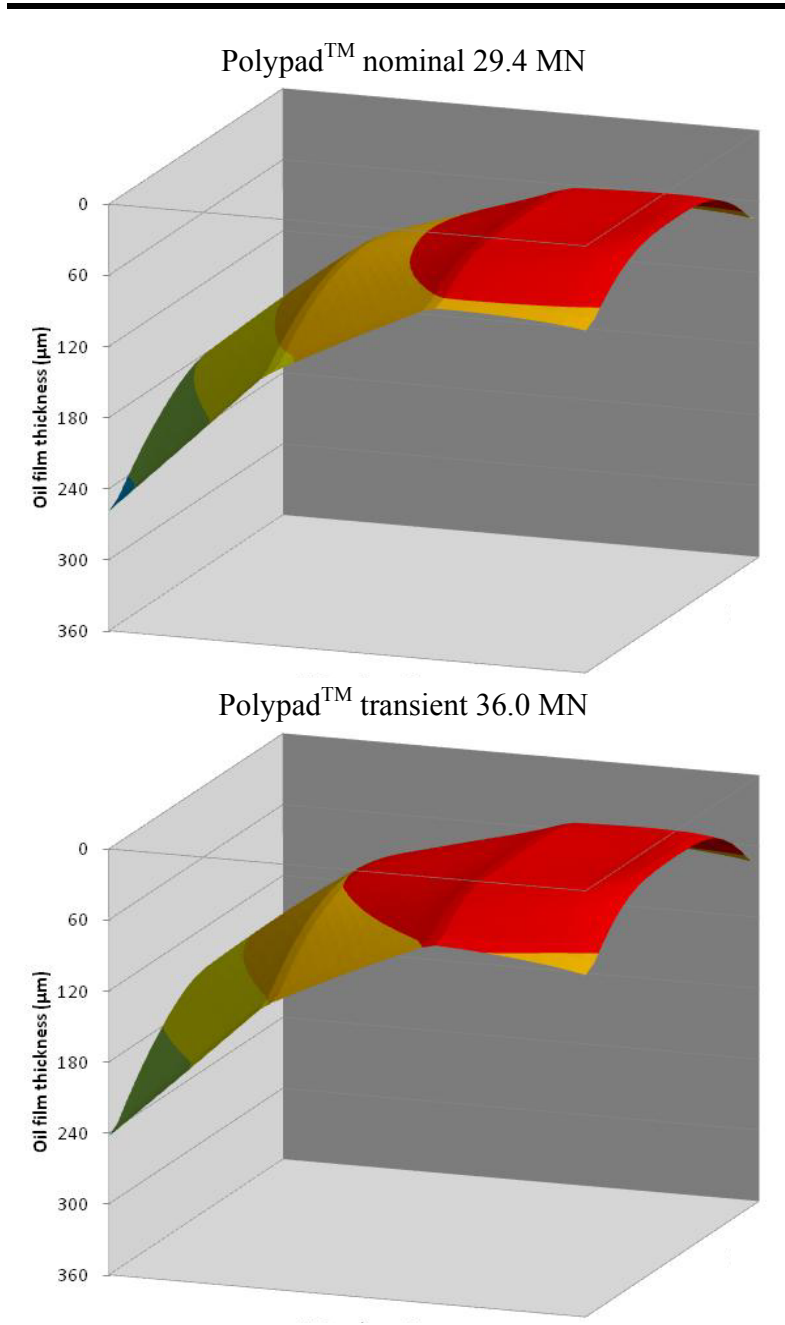

Fig. 16 Comparison of the oil film thickness geometries.

The most interesting results of the transient bearing operation are given in Fig. 16-19. The thrust bearing behaviour under high load (specific pressure higher than $7 \mathrm{MPa}$ ) is in general similar to the rated condition. Minimum oil film thickness reduced from $27 \mu \mathrm{m}$ to 21 $\mu \mathrm{m}$ but remained 

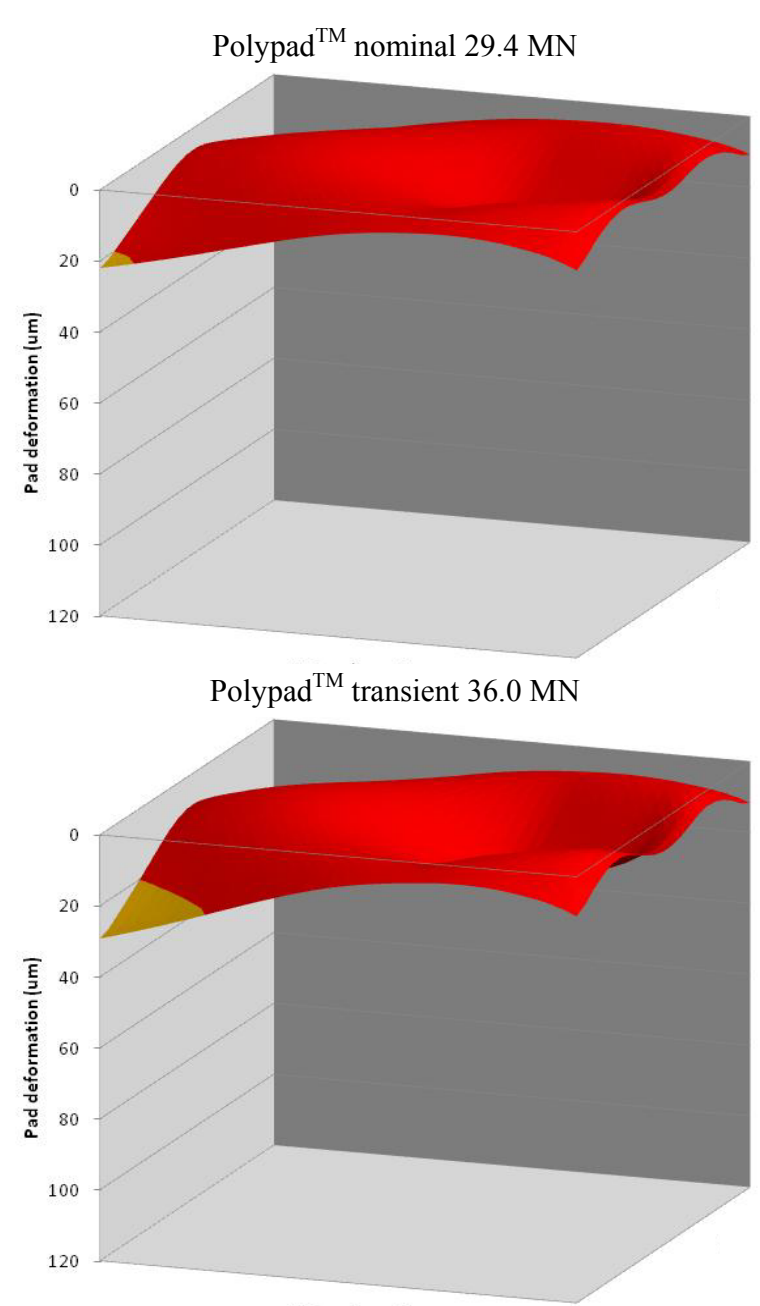

Fig. 17 Comparison of the thrust pad deformations.

still within the safe region above $20 \mu \mathrm{m}$. Maximum oil film temperature increased from $94.4{ }^{\circ} \mathrm{C}$ to $99.0{ }^{\circ} \mathrm{C}$ which is still very safe value from the bearing coating as well as from the oil durability point of view. Maximum to specific pressure ratio increased from 3.0 to 3.2 indicating higher impact of the runner thermal crowning. Power losses increased slightly from 325.3 $\mathrm{kW}$ to $339.4 \mathrm{~kW}$ due to higher shear stresses in the thinner oil film.

Thermo-elastic deformations of the polymer coated surface indicate slightly higher values which lead to even better compensation of the thrust runner thermal crowning.

Maximum pressure values increased compared to rated condition but the pressure field remained very similar. It still shows very clearly a filled profile in the
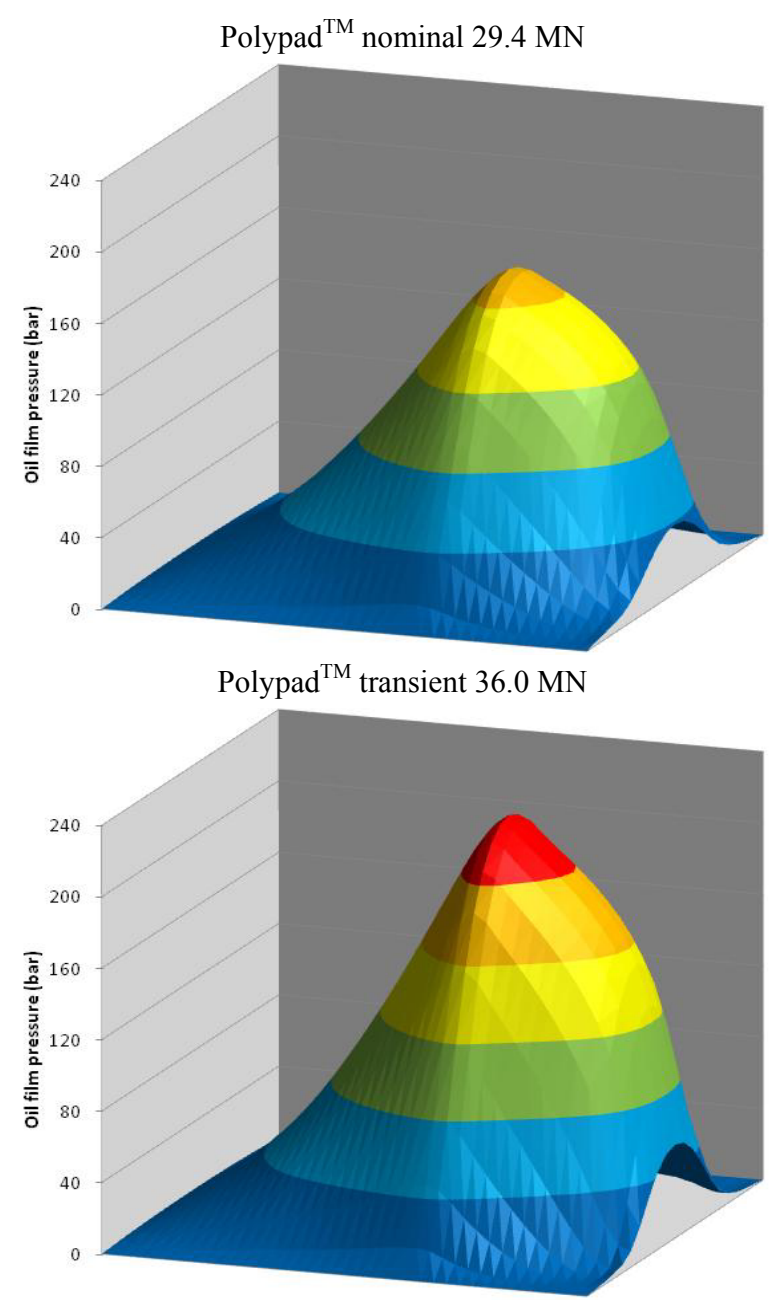

Fig. 18 Comparison of the hydrodynamic pressure fields.

oil film outlet zone. This indicated one of the main advantages of the polymer lined bearings-self adaptation. Due to high elasticity of the coating, there is no divergent oil film region and consequently the pad area is utilized in optimal way. It results finally in uniform pressure distribution and high load carrying capacity of the whole bearing.

In the oil film cross section, one can observe vital impact of the tapered bearing design on the hydrodynamic behavior of the bearing. Even though the thrust load is very high, the oil film remained convergent with reasonably high oil film outlet to inlet height ratio.

\section{Conclusions}

In the paper, it has been shown that it is possible to 


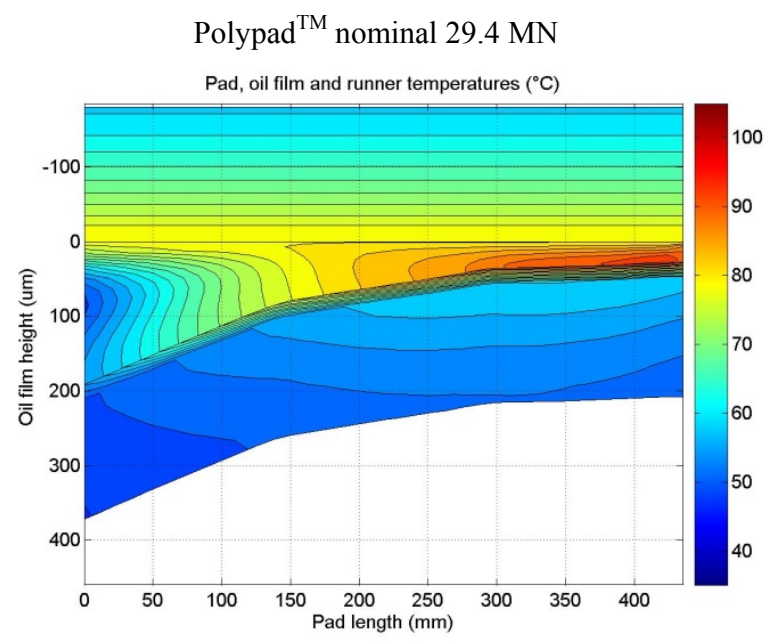

Polypad $^{\mathrm{TM}}$ transient 36.0 MN

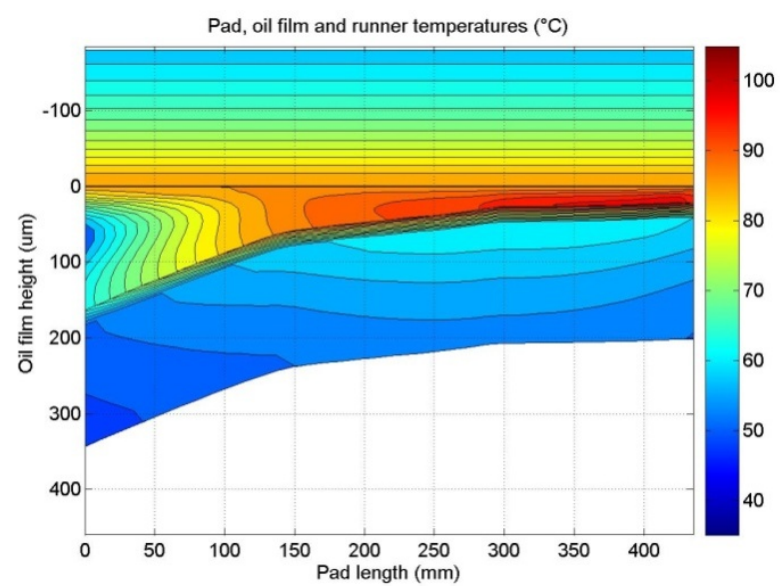

Fig. 19 Temperature fields on the cross section through the bearings for average radius $(R=2,112.5 \mathrm{~mm})$.

optimize thrust bearing design of Itaipu hydro generator without loss of the operational safety. Modern materials and computational techniques allow to extend the operational limits of the hydrodynamic bearings. The bearing showed very good operational performance for both rated and transient conditions. Due to self-adjusting ability of polymer coated bearings, the behavior under transient load, with specific pressure exceeding $7 \mathrm{MPa}$, was shown to be very satisfactory.
Further investigations are necessary in order to prove economic and technological need of such an upgrade.

Definitely polymer coated thrust bearings are an option for consideration during design process of a new hydro generators. In such case, cost savings during project execution as well as power loss savings during whole operational lifetime justify implementation of such bearing technology.

\section{References}

[1] Leopard, A. J. 1976. "Tilting Pad Bearings—Limits of Operation.” Lubrication Engineering 32 (12): 637-44.

[2] Cotrim, J. R. 1994. Itaipu Hydroelectric Project: Engineering Features. Curitiba: Itaipu Binacional.

[3] Kraft, C., and Schwarze, H. 2012. „Improved Axial Hydrodynamic Bearing Calculation. Heavy Loaded, High Speed Axial Bearings in Simple and Double Arrangement Considering Static Misalignment of the Runner Surface." FVV-Vorhaben Nr. 1002, Abschlussbericht, Clausthal. (in German)

[4] Ettles, C. M. 1980. "Size Effects in Tilting Pad Thrust Bearings." Wear 59 (1): 231-45.

[5] Wodtke, M., Schubert, A., Fillon, M., Wasilczuk, M., and Pajaczkowski, P. 2010. "Large Hydrodynamic Thrust Bearing-Comparison of the Calculations and Measurements." Presented at the 9th EDF/Pprime (LMS) Workshop, Poitiers, France.

[6] Glavatskih, S., and Fillon, M. 2008. "PTFE-Faced Centre Pivot Thrust Pad Bearings: Factors Affecting TEHD Performance." Tribology International 41 (12): 1219-25.

[7] Pajaczkowski, P., Schubert, A., and Brescianini, T. 2010. "Centrally Pivoted Tilting Pad Thrust Bearing with Inlet and Outlet Tapers-Measurements vs. TEHD Investigations." Presented at the 9th EDF/Pprime (LMS) Workshop, Poitiers, France.

[8] Pajaczkowski, P., and Schubert, A. 2013. "Implementation of the Tapered Tilting Pad Thrust Bearing Design in a High Speed PSP Hydro Generator." Presented at the 12th EDF/Pprime (LMS) Workshop, Poitiers. 